\section{Second eye of patients with unilateral neovascular age- related macular degeneration: Caucasians vs Chinese}

S Sivaprasad ${ }^{1,2}$, WL Membrey ${ }^{1}, \mathrm{~V}$ Sivagnanavel', JG Gonzalez', DTL Liü, WM Chan ${ }^{3}$, DSC Lam³, H Jackson ${ }^{2}$ and NV Chong'

\section{Abstract}

Purpose To investigate the correlation between morphological features of choroidal neovascularisation $(\mathrm{CNV})$ secondary to agerelated macular degeneration (AMD) in the first eye and the severity of age-related maculopathy (ARM) in the fellow eyes in two racial groups: Caucasians and Chinese. Participants A total of 135, fluorescein angiograms of patients with unilateral neovascular AMD and ARM in the fellow eyes were included in the study: 38 Caucasians from King's College Hospital, UK; 45 Caucasians from West Kent Eye Centre, UK; 52 Chinese from Hong Kong Eye Hospital, Hong Kong. Main outcome measures CNV subtype in the affected eye and ARM severity in the second eyes. Results Although the proportion of CNV subtypes in the three groups were similar, the Chinese cohort showed significantly less ARM severity compared to the Caucasian cohorts $(P<0.05)$.

Conclusion Although drusen and retinal pigmentary changes may be prognostic indicators of $\mathrm{CNV}$, this study suggest that other factors contribute significantly to the pathogenesis of CNV in AMD.

Eye (2006) 20, 923-926. doi:10.1038/sj.eye.6702056; published online 26 August 2005

Keywords: Drusen; racial differences; macular degeneration

\section{Introduction}

Neovascular age-related macular degeneration (NVAMD) is the leading cause of severe visual loss in patients above the age of 50 years in the Western world. ${ }^{1-3}$ A number of epidemiological studies in several races and ethnic groups suggest that NVAMD is no longer a threat only to the Western population, but is emerging as a global cause of blindness in the elderly. ${ }^{4-10}$

Based on clinical observations, the epidemiological features and predisposing factors for the development of choroidal neovascularisation (CNV) have been found to vary in different racial groups. ${ }^{11}$ Natural history studies on fellow eyes of patients with unilateral NVAMD have identified important determinants for the development of $\mathrm{CNV}^{12-16}$ The characteristics of drusen are an important indicator of the type of neovascular lesion in Caucasians. ${ }^{17}$ Abugreen et al ${ }^{18}$ reported that the severity of age-related maculopathy (ARM) in the fellow eye correlates with the CNV subtype in the affected eye of patients with unilateral NVAMD. They observed that patients with occult or minimally classic $\mathrm{CNV}$ in the affected eye had more severe form of ARM in the fellow eye compared to the fellow eyes of predominantly classic $\mathrm{CNV}$.

In this study, we examined the relation between the morphological features of $\mathrm{CNV}$ in the first eye with the severity of ARM in the fellow eyes in two racial groups: Caucasians and Chinese.

\section{Patients and methods}

Consecutive colour fundus photographs and fluorescein angiogram images were examined from the digital retinal photography databases from three centres: King's College Hospital, UK,
${ }^{1}$ Retinal Research Unit, King's College Hospital, Denmark Hill, London, UK

${ }^{2}$ West Kent Eye Centre, Princess Royal University Hospital, Orpington, Kent, UK

\section{${ }^{3}$ Department of} Ophthalmology and Visual Sciences, Chinese University of Hong Kong, Hong Kong Eye Hospital, Kowloon, Hong Kong, People's Republic of China

Correspondence: N Victor Chong, Retinal Research Unit, King's College Hospital, Normandy Building, Denmark Hill, London SE5 9RS, UK Tel: + 44207 3464548; Fax: + 442073463738

E-mail: victor@

eretina.org

Received: 4 February 2005 Accepted in revised form: 28 June 2005

Published online: 26 August 2005

None of the authors have any proprietary or financial interest in this project 
West Kent Eye Centre, UK, and Prince of Wales Hospital, Hong Kong.

The inclusion criteria were as follows: age $>50$ years; evidence of macular CNV in one eye using the Macular Photocoagulation Study (MPS) group definition ${ }^{19}$ and ARM in the fellow eye (Grade $0 \mathrm{~b}-3$ based on Rotterdam Study). ${ }^{20}$ Only Caucasian patients were included from the two UK centres and only Chinese patients were included from the centre in Hong Kong.

Exclusion criteria included: CNV secondary to other causes such as myopia, post-inflammatory and angioid streaks; retinal features suggestive of polypoidal choroidal vasculopathy; ungradeable CNV due to poor photographic quality.

The CNV subtype was determined from colour fundus photographs and early, mid and late frames of fluoresein angiograms, while the grade of ARM in the fellow eye was determined from colour fundus photographs. The images were cropped using the same template with Adobe Photoshop software version 7.0 (๑ Adobe systems incorporated 1990-2002) to delete any peripheral image features that might identify the site of origin. The images for each patient from each site were stored in separate folders and these were combined and recoded in random order by one of the authors not involved in the grading.

\section{Grading}

Grading of the digital colour photographs and fluorescein angiograms was performed by two independent graders from King's College Hospital. Any discrepancies were resolved by the senior author.

The CNV subtype in the affected eye was classified as shown below:

1. Predominantly classic CNV (PC) where the area of classic CNV $>50 \%$ of the area of the entire lesion.

2. Minimally classic $\mathrm{CNV}(\mathrm{MC})$ where the area of the classic $\mathrm{CNVM}$ is $<50 \%$ and $>0 \%$ of the entire lesion.

3. Occult CNV with no classic component (OC) included both fibrovascular pigment epithelial detachment and late leakage of undetermined source.

ARM in the second eye was graded according to the classification used in the Rotterdam study. For the purpose of analysis, following grading of ARM in the fellow eye into grades 0a to 3, all patients with ARM grade $0 \mathrm{a}$ were excluded in order to avoid inclusion of patients with idiopathic CNV. Each fellow eye was then assigned an ARM severity grade 1-6 so that each increasing grade of ARM corresponded to a one-point rise in ARM severity as shown in Table 1 .

\section{Statistical analysis}

Data were analysed using the statistical package for the social sciences SPSS 11.0.0. (SPSS Inc., Chicago, IL, USA). Agreement between graders was assessed using Cohen's kappa statistics. Univariate analysis was done to explore the relationship between severity of ARM and CNV subtypes. Multiple ordinal analyses using STATA 7-8 were performed to determine the ARM severity in the three subtypes of $\mathrm{CNV}$ in the three groups (two Caucasians and one Chinese).

\section{Results}

A total of 135 patients were included in the study. In all, 38 Caucasians were recruited from King's College Hospital (KCH), UK, 45 Caucasians from West Kent eye Centre (WKEC), UK, and 52 Chinese from Prince of Wales Hospital (PWH), Hong Kong.

The mean ARM severity score is compared in the two groups (Caucasian and Chinese cohort) in Table 2. On univarite analysis, the Chinese cohort showed significantly less ARM severity compared to the Caucasian group (mean difference $=1.0 ; 95 \%$ CI 0.31-1.8; $P=0.005)$.

Although the proportion of CNV subtypes in the two ethnic groups was similar (Table 3); multiple ordinal regression analysis showed that the mean ARM severity

Table 1 ARM severity scale based on the Rotterdam Study

\begin{tabular}{llc}
\hline $\begin{array}{l}\text { Rotterdam } \\
\text { study }\end{array}$ & Definition of ARM & $\begin{array}{c}\text { ARM } \\
\text { severity } \\
\text { scale }\end{array}$ \\
\hline $0 \mathrm{~b}$ & $\begin{array}{l}\text { Hard drusen }(<63 \mu \mathrm{m}) \text { only } \\
\text { Soft distinct drusen }(\geq 63 \mu \mathrm{m}) \\
\text { only }\end{array}$ & 1 \\
$\mathrm{la}$ & $\begin{array}{l}\text { Pigment abnormalities only (no } \\
\text { soft drusen) }\end{array}$ & 3 \\
$\mathrm{1b}$ & $\begin{array}{l}\text { Soft indistinct drusen }(\geq 125 \mu \mathrm{m}) \\
\text { or reticular drusen only } \\
\text { Soft distinct drusen }(\geq 63 \mu \mathrm{m})\end{array}$ & 4 \\
$2 \mathrm{a}$ & $\begin{array}{l}\text { with pigment abnormalities } \\
\text { Soft indistinct drusen }(\geq 125 \mu \mathrm{m}) \\
\mathrm{ob}\end{array}$ & 5 \\
3 & $\begin{array}{l}\text { or reticular drusen with pigment } \\
\text { abnormalities }\end{array}$ & 6 \\
\hline
\end{tabular}

Table 2 Mean ARM severity in fellow eyes of the 2 races

\begin{tabular}{lcc}
\hline Race & $\mathrm{N}(\%)$ & Mean ARM severity (95\% CI) \\
\hline Caucasians & $83(61)$ & $2.5(1.9-3.2)$ \\
Chinese & $52(39)$ & $1.4(1-2)$ \\
Total & $135(100)$ & $2.0(1.8-2.4)$ \\
\hline
\end{tabular}


in the Chinese cohort was significantly less than the Caucasian population $(P=0.001)$.

When we correlated the CNV subtype in the affected eye with the ARM severity in the fellow eye, predominantly the classic group showed significantly less ARM severity in the fellow eye compared to the minimally classic and occult $\mathrm{CNV}$ groups in the Caucasian group as previously reported. However, the Chinese cohort did not show a similar pattern. The CNV subtype did not correlate to the ARM severity in the Chinese group (Table 4).

\section{Discussion}

The incidence of CNV in the fellow eyes of Caucasians is high with prospective studies estimating the incidence of 6-8.8\%/year. ${ }^{15,21}$ MPS study reported that CNV developed in $35 \%$ of fellow eyes within 5 years. Data from the Asian population suggest a lower incidence of CNV in the second eye. .,8,22 $^{2}$

The MPS study has shown that characteristics of drusen and retinal pigmentary abnormalities are independent prognostic indicators for development of CNV. ${ }^{15,16}$ These findings have been quantified in large population-based studies ${ }^{1-3}$ and they provide a strong rationale for using these features to design a universally accepted grading system for stratifying ARM. The Rotterdam study incorporates the International ARM Epidemiological study group nomenclature to classify ARM into mutually exclusive stages. ${ }^{20,23}$ Early ARM is

Table 3 CNV subtypes in the two ethnic groups

\begin{tabular}{lccc}
\hline Race & $\begin{array}{c}\text { Predominantly } \\
\text { classic CNV (\%) }\end{array}$ & $\begin{array}{c}\text { Minimally classic Pure occult CNV } \\
\text { CNV (\%) }\end{array}$ & $(\%)$ \\
\hline Chinese & $15(29)$ & $10(19)$ & $27(52)$ \\
Caucasians & $25(30)$ & $16(19)$ & $42(51)$ \\
$P$-value & NS & NS & NS \\
\hline
\end{tabular}

NS: nonsignificant.

Table 4 Mean ARM severity in fellow eye categorised by CNV subtype in affected eye

\begin{tabular}{|c|c|c|}
\hline Race & CNV subtypes & Mean ARM severity \\
\hline \multirow[t]{3}{*}{ Chinese } & Predominantly classic CNV & 1.5 \\
\hline & Minimally classic CNV & 1.4 \\
\hline & Pure occult CNV & 1.3 \\
\hline \multirow[t]{3}{*}{ Caucasians } & Predominantly classic CNV & 2.0 \\
\hline & Minimally classic CNV & 2.5 \\
\hline & Pure occult CNV & 3.0 \\
\hline
\end{tabular}

defined as the presence of drusen and/or retinal pigment epithelial abnormalities in the absence of late ARM.

Based on this grading system, it has been observed that ARM characteristics in the fellow eye correlate with the type of CNV in the affected eye. The fellow eyes of predominantly classic CNV have significantly less severe ARM compared to the fellow eyes with occult $\mathrm{CNV} .^{18}$

In this study, we also used the Rotterdam classification to assess ARM severity in the fellow eyes of Caucasian and Chinese patients with unilateral NVAMD. Our data suggests that a clear relation exists between increasing severity of ARM in the fellow eye and the proportion of occult CNV in the affected eye in the Caucasians, but the Chinese cohort developed CNV at a much lower severity of ARM.

The prevalence of drusen and retinal pigmentary abnormalities in the oriental races has been observed to be less than that in Caucasians. ${ }^{7,23,24}$ In the Caucasian population, drusen characteristics such as soft drusen and large and confluent drusen are particularly high risks for developing $\mathrm{CNV}$, corresponding to grade $2 \mathrm{a}-3 .^{25-27}$ However, soft drusen are not as prevalent in the Orientals..$^{22,24,28}$ In addition, the prevalence of retinal pigmentary changes is lower in the Orientals. ${ }^{22}$ These findings contribute to the fact that the Chinese cohort has less ARM severity compared to Caucasians.

However, this study also shows that the proportion of CNV subtypes in the different races is similar. Therefore, it suggests that though drusen and retinal pigmentary changes may be prognositic indicators of $\mathrm{CNV}$, other factors contribute significantly to the pathogensis of $\mathrm{CNV}$ in AMD. This is further substantiated by the fact that serous pigment epithelial detachments (PED) were found to be a higher risk factor for development of $\mathrm{CNV}$ in the Chinese and Japanese compared to soft drusen. ${ }^{22,24,28}$ Serous PEDs are not included in the Rotterdam grading. It may be that if ARM severity is analysed by including all morphological abnormalities in the retina, there may not be significant differences in ARM severity between races.

The present study is limited by its retrospective series and cross-sectional approach. Further longitudinal studies of fellow eyes with unilateral NVAMD in different races are required to assess risk factors in fellow eyes in various races.

\section{References}

1 Klein R, Klein BE, Tomany SC, Meuer SM, Huang GH. Tenyear incidence and progression of age-related maculopathy: The Beaver Dam Eye study. Ophthalmology 2002; 109: 1767-1779.

2 van Leeuwen R, Klaver CC, Vingerling JR, Hofman A, de Jong PT. The risk and natural course of age-related 
maculopathy: follow-up at 6 and a half years in the Rotterdam study. Arch Ophthalmol 2003; 121: 519-526.

3 Wang JJ, Foran S, Smith W, Mitchell P. Risk of age-related macular degeneration in eyes with macular drusen or hyperpigmentation: The Blue Mountains Eye study cohort. Arch Ophthalmol 2003; 121: 658-663.

4 Wu LZ, Chen YZ, Chao XY, Huang ZS, Xu XJ, Xin DY et al. Aging macular degeneration in Tibetan and Han. Eye Sci 1987; 3: 179-181.

5 Wu LZ, Chen YZ, Liu AQ, Li DY, Tang SB, Xu ZZ et al. Aging macular degeneration in Uighur. Eye Sci 1987; 3: 175-178.

6 Wu ZQ. Epidemiologic survey of senile macular degeneration. Chinese J Ophthalmol 1992; 28: 246-247.

7 Yuzawa M, Tamakoshi A, Kawamura T, Ohno Y, Uyama M, Honda T. Report on the nationwide epidemiological survey of exudative age-related macular degeneration in Japan. Int Ophthalmol 1997; 21: 1-3.

8 Oshima Y, Ishibashi T, Murata T, Tahara Y, Kiyohara Y, Kubota T. Prevalence of age related maculopathy in a representative Japanese population: The Hisayama study. $\mathrm{Br}$ J Ophthalmol 2001; 85: 1153-1157.

9 Miyazaki M, Nakamura H, Kubo M, Kiyohara Y, Oshima Y, Ishibashi $\mathrm{T}$ et al. Risk factors for age related maculopathy in a Japanese population: The Hisayama study. Br J Ophthalmol 2003; 87: 469-472.

10 Jain IS, Prasad P, Gupta A, Ram J, Dhir SP. Senile macular degeneration in northern India. Ind J Ophthalmol 1984; 32: 343-346.

11 Klein R, Peto T, Bird A, Vannewkirk MR. The epidemiology of age-related macular degeneration. Am J Ophthalmol 2004; 137: 486-495.

12 Gregor Z, Bird AC, Chisholm IH. Senile disciform macular degeneration in the second eye. $\mathrm{Br} J$ Ophthalmol 1977; 61: 141-147.

13 Roy M, Kaiser Kupfer M. Second eye involvement in age-related macular degeneration. A four year prospective study. Eye 1990; 4: 813-818.

14 Pieramici DJ, Bressler SB. Age-related macular degeneration and risk factors for the development of choroidal neovascularisation in the fellow eye. Curr Opin Ophthalmol 1998; 9: 38-46.

15 Macular Photocoagulation Study Group. A five-year followup of fellow eyes of patients with age-related macular degeneration. Arch Ophthalmol 1993; 111: 1189-1199.

16 Macular Photocoagulation Study Group. Risk factors for choroidal neovascularization in the second eye of patients with juxtafoveal or subfoveal choroidal neovascularization secondary to age-related macular degeneration. Arch Ophthalmol 1997; 115(6): 741-747.

17 Pauleikhoff D, Barondes MJ, Minassian D, Chisholm IH, Bird AC. Drusen as risk factors in age-related macular disease. Am J Ophthalmol 1990; 109: 38-43.

18 Abugreen S, Muldrew KA, Stevenson MR, VanLeeuwen R, DeJong PT, Chakravarthy U. CNV subtype in first eyes predicts severity of ARM in fellow eyes. $\mathrm{Br} J$ Ophthalmol 2003; 87(3): 307-311.

19 Macular Photocoagulation Study Group. Subfoveal neovascular lesions in age-related macular degeneration. Guidelines for evaluation and treatment in the Macular Photocoagulation Study. Arch Ophthalmol 1991; 109: 1242-1257.

20 Klaver CCW, Assink JJM, van Leeuwen R, Wolfs RC, Vingerling JR, Stijnen Tet al. Incidence and progression rates of age-related maculopathy: the Rotterdam Study. Invest Ophthalmol 2001; 42: 2237-2241.

21 Sanberg MA, Weiner A, Miller S, Gaudio AR. High risk characteristics of fellow eyes of patients with unilateral neovascular age-related macular degeneration. Ophthalmology 1998; 105: 441-447.

22 Uyama M, Takahashi K, Ida N, Miyashiro M, Ando A Takahashi A et al. The second eye of Japanese patients with unilateral exudative age related macular degeneration. $\mathrm{Br} J$ Ophthalmol 2000; 84(9): 1018-1023.

23 Bird AC, Bressler NM, Bressler SB, Chisholm IH, Coscas G, Davis MD et al. An international classification and grading system for age-related maculopathy and age-related macular degeneration. The International ARM Epidemiological Study Group. Surv Ophthalmol 1995; 39: 367-374.

24 Lim JI, Kwok A, Wilson D. Symptomatic age-related macular degeneration in Asian patients. Retina 1998; 18: 435-438.

25 Gass JDM. Drusen and disciform macular detachment and degeneration. Arch Ophthalmol 1973; 90: 206-217.

26 Teeters VW, Bird AC. The development of neovascularization of senile disciform macular degeneration. Am J Ophthalmol 1973; 76: 1-18.

27 Strahlman ER, Fine SL, Hillis A. The second eye of patients with senile macular degeneration. Arch Ophthalmol 1983; 101: 1191-1193.

28 Yuzawa M, Hagita K, Egawa T, Minato H, Matsui M. Macular lesions predisposing to senile disciform macular degeneration. Jpn J Ophthalmol 1991; 35: 87-95. 